\title{
Cholecystokinin-Dopamine Coexistence: Electrophysiological Actions Corresponding to Cholecystokinin Receptor Subtype
}

\author{
D. W. Hommer, G. Stoner, J. N. Crawley, S. M. Paul, and L. R. Skirboll \\ Electrophysiology Unit, Clinical Neuroscience Branch, National Institute of Mental Health, Bethesda, MD 20205
}

\begin{abstract}
Cholecystokinin (CCK)-like peptides when administered intravenously produce 2 distinct actions on the single-unit activity of mesencephalic dopamine (DA) neurons in the rat: an excitatory action and a potentiation of the inhibitory effects of $\mathrm{DA}$ agonists. The ability of several CCK fragments that have been shown to bind selectively to the peripheral and/or the central CCKbinding sites were examined for their ability to induce either excitation or a potentiation of DA. Only sulfated CCK-8 was able to induce excitation of mesencephalic DA neurons, but both sulfated and unsulfated CCK-8, as well as CCK-4, potentiated the inhibitory effects of the DA agonist apomorphine (APO). CCK-3 failed to potentiate APO-induced inhibition. Both of these effects appeared to be confined to cell bodies in regions of the ventral tegmental area and substantia nigra, zona compacta that have been reported to contain both DA and CCK. Thus, CCKlike peptides that have been shown to bind to the high-affinity CCK binding site in brain potentiated the effects of DA. In contrast, the ability of CCK-like peptides to induce neuronal excitation corresponds with their affinity for the peripheral-type CCK binding site.
\end{abstract}

Immunohistochemical studies have revealed that dopamine (DA) and cholecystokinin (CCK) coexist in a subpopulation of midbrain mesencephalic neurons previously considered to contain DA alone (Hökfelt et al., 1980a, b). Further studies in the rat have demonstrated that these CCK-DA containing neurons project primarily to limbic structures, including the nucleus accumbens, central nucleus of the amygdala, olfactory tubercle, and prefrontal cortex. Thus, the anatomical distribution of CCKDA cell bodies suggests that CCK may play a selective role in the modulation of mesolimbic DA function.

CCK has been shown to possess several neurotransmitter-like properties. For example, CCK is released following depolarization in a calcium-dependent fashion (Meyer and Krause, 1983; Pinget et al., 1979), and specific binding sites for CCK have been demonstrated in many brain regions (Hays et al., 1980; Saito et al., 1980). The distribution of these binding sites correlates with the distribution of CCK-containing neurons, as demonstrated by immunohistochemical methods (Gaudreau et al., 1983; Zarbin et al., 1983). Electrophysiologically, CCK has been shown to produce excitatory effects in a variety of systems (Dodd and Kelly, 1981; Jeftiniji et al., 1981; Rogawski, 1982; Salt and Hill, 1982) including the presynaptic (Skirboll et al., 1981) and postsynaptic (White and Wang, 1984) neurons of the mesolimbic DA system. There have been reports that CCK increases the affinity and decreases the number of central DA receptors (Murphy and Schuster, 1983), as well as decreasing

\footnotetext{
Received Dec. 30, 1985; revised Mar. 17, 1986; accepted Mar. 18, 1986.

Correspondence should be addressed to Dr. Daniel W. Hommer, Clinical Neuroscience Branch, NIMH, Bldg. 10, Room 4N214, Bethesda, MD 20892.
}

Copyright (C) 1986 Society for Neuroscience 0270-6474/86/103039-05\$02.00/0
DA turnover in several regions of the rat forebrain (Fuxe et al., 1981). In addition, other studies have shown that CCK can suppress the release of DA in rat and cat brain (Markstcin and Hökfelt, 1984; Voight and Wang, 1984).

The DA agonist apomorphine (APO) has been known for some time to effectively inhibit the firing of DA neurons in the substantia nigra by acting on autoreceptors (Skirboll et al., 1979). Recently, we reported that sulfated CCK (CCK-S) potentiated the ability of APO to inhibit the firing of CCK-DA-containing neurons in the medial substantia nigra zona compacta (SNC) (Hommer and Skirboll, 1983). We have confirmed and extended our results by demonstrating that CCK-S injected directly into the nucleus accumbens, an area rich in CCK-DA terminals, potentiates the behavioral actions of APO (Crawley et al., 1984, $1985 \mathrm{a}, \mathrm{b})$. Furthermore, topographical studies of the intra-accumbens site of CCK administration revealed a good correlation between coexistent regions and the degree of potentiation of the APO response (Crawley et al., 1985a, b). These investigators also injected CCK into the caudate nucleus, an area rich in both CCK and DA but in which there is no immunohistochemical evidence that these putative transmitters coexist. In this location, CCK failed to potentiate APO-induced behavior. These data taken together suggest that the ability of CCK to modulate the actions of DA has at least some degree of anatomical specificity, i.e., it is limited to the areas richest in CCK-DA coexistence. In this paper, we extend these findings to suggest that this specificity also encompasses the CCK-modulated responses at the DA cell body.

Evidence has been presented by various laboratories that there are specific binding sites in brain for CCK (Hays et al., 1980; Saito et al., 1980). In this regard, there has also been a growing literature on the differences between the so-called peripheral and central CCK binding sites (Hays et al., 1980; Knight et al., 1984; Steigerwalt and Williams, 1984; Van Dijk et al., 1984). Evidence has been presented that the so-called central binding sites correlate quite well with areas that show CCK-like immunoreactivity (Gaudreau et al., 1983; Van Dijk et al., 1984; Zarbin et al., 1983). Studies of the peripheral and central binding sites for CCK have reported different pharmacologic profiles in terms of potency of binding for a series of CCK analogs, including CCK-S and unsulfated CCK-8 (CCK-US), CCK-4, and CCK-3 (Gaudreau et al., 1983; Hays et al., 1980; Knight et al., 1984; Moran et al., 1985; Saito et al., 1981; Steigerwalt and Williams, 1984; Van Dijk et al., 1984; Wennogle et al., 1985). These findings are of particular interest in light of our reports that CCK has 2 distinct actions in the substantia nigra, i.e., excitation and facilitation of the actions of APO. Thus, in an effort to examine the relationship between these 2 responses and the central CCK receptor, we examined the functional actions of a variety of CCK analogs. By this approach we hoped to determine if the different effects of CCK, i.e., excitation and/or modulation of the actions of DA, were mediated through specific brain-type or peripheral-type CCK binding sites. 


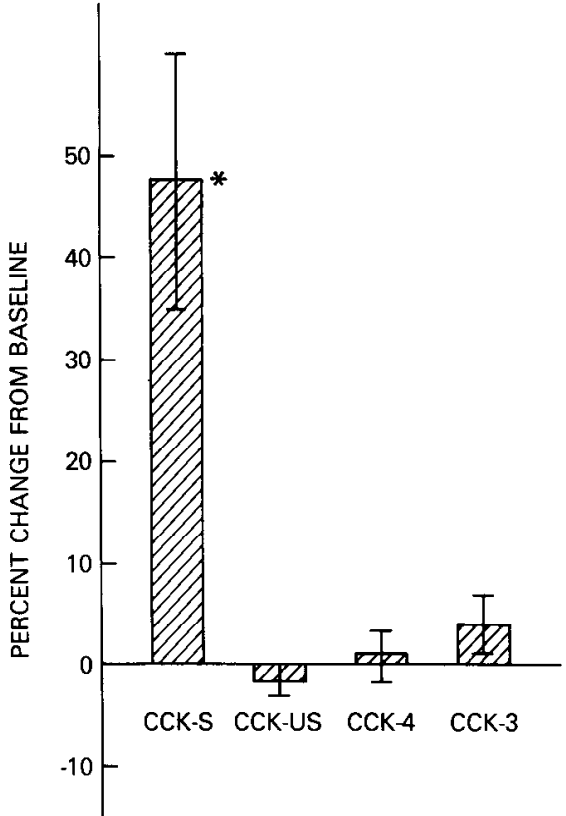

Figure 1. Intravenous administration of sulfated CCK $(20 \mu \mathrm{g} / \mathrm{kg})$ leads to a highly significant increase in the firing rate of dopamine neurons in the medial A-9, lateral A-10 region. Other forms of CCK did not excite these neurons. ${ }^{*} p<0.001$; bars indicate SEM $(n=6$ for each peptide).

\section{Materials and Methods}

\section{Recording techniques}

Male Sprague-Dawley rats weighing between 200-260 g were used throughout these experiments. Animals were anesthetized with chloral hydrate $(400 \mathrm{mg} / \mathrm{kg}$, i.p.) and maintained under anesthesia during the course of the experiment with additional chloral hydrate (i.v.) as needed. Rats were mounted in a stereotaxic apparatus, the scalp and periosteum reflected, and a $3 \mathrm{~mm}$ burr hole drilled over 1 of the 2 regions: the medial substantia nigra-lateral ventral tegmentum (SN-VT) or the more lateral region of the substantia nigra zona compacta (LZC). the SNVT region is an area of DA-containing cell bodies many of which also contain CCK as a cotransmitter (Hökfelt et al., 1980a, b). Cells in this region respond to systemic and ionotophoretically administered CCK

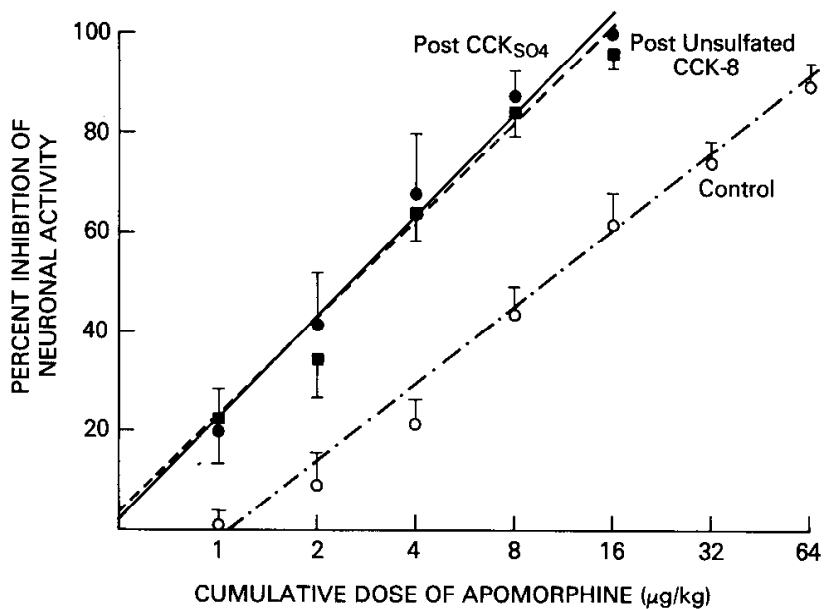

Figure 2. Cumulative log dose-response curves of the effects of intravenously administered APO on the activity of MSN-LVT DA cells following pretreatment with saline control (O-.-.- $)$, unsulfated CCK-8 $(\square-\cdots)$, or sulfated CCK $(-\bullet)(n=6$ for each group).

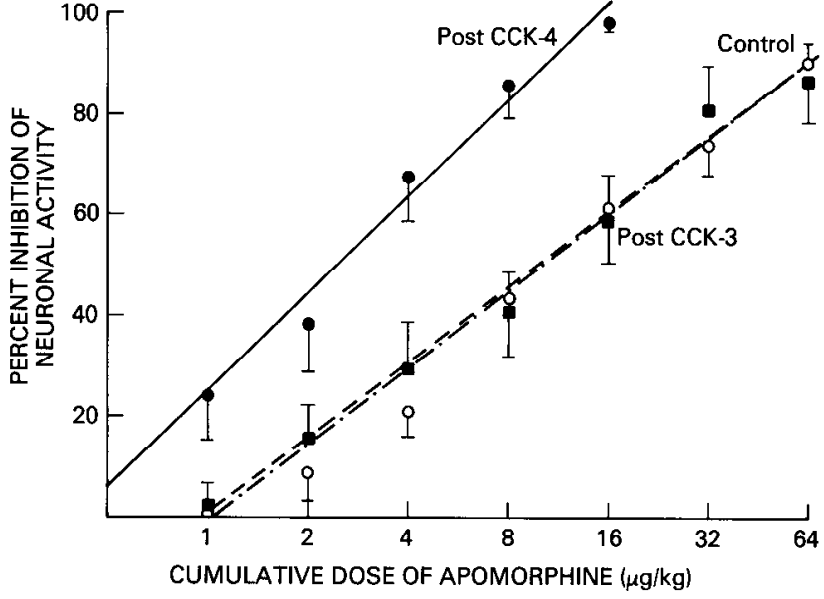

Figure 3. Cumulative log dose-response curves of the effects of intravenously administred APO on the activity of MSN-LVT DA cells following pretreatment with saline control $\left(\mathrm{O}^{-} \cdot--\mathrm{O}\right)$, CCK-3 ( or CCK-4 $(-)$ ).

by increasing their firing rate (Skirboll et al., 1981). The LZC also contains DA cell bodies, but fewer cells show CCK immunoreactivity, and cells in this region have been shown to be unresponsive to CCK administration (Skirboll et al., 1981). Recordings from SN-VT neurons were taken from a region defined on the basis of the atlas of Paxinos and Watson (1982) as $0.6-1.2 \mathrm{~mm}$ lateral to the midline and 3.4-4.0 anterior to the interaural line. Recordings from the LZC included an area $2.0-2.6 \mathrm{~mm}$ lateral to the midline and $3.4-4.0$ anterior to the interaural line.

Single-barrel micropipettes (WPI 1B150F) filled with a $2 \mathrm{M} \mathrm{NaCl}$ solution saturated with $2 \%$ pontamine sky blue and with an impedance of $6 \pm 2 \mathrm{~m} \Omega$ (measured at $60 \mathrm{~Hz}$ ) were used. Electrodes were lowered into the brain using a Burleigh "Inchworm" microdrive (Burleigh Instruments). Electrode potentials were passed through a high-impedance amplifier (WPI 750) and monitored on an oscilloscope (Tektronix F613) and a audiomonitor (Grass AM8). The firing of single units was counted over $10 \mathrm{sec}$ epochs using a window discriminator and a rate meter (NIMH Instrumentation Section) and the rates displayed on a chart recorder (Gould 2200S) and a thermal printer (Datel CDPP-7). Core body temperature was monitored with a thermistor rectal probe and was maintained with a heating pad at $36-37^{\circ} \mathrm{C}$. Cells were identified as DA neurons on the basis of spike duration $(>2 \mathrm{msec}$ ), shape (initial notched segment followed by a triphasic potential), and firing rate $(<9$ spikes/sec) (Bunney et al., 1973). Intracellular recordings from units with these characteristics combined with L-DOPA injections and subsequent histological examination have confirmed that they are DAcontaining neurons (Grace and Bunney, 1980).

\section{Drug administration and neuronal response}

All drugs were given intravenously through a lateral tail vein. The CCK-S used in these experiments was either the heptapeptide (a generous gift of Drs. V. Mutt and T. Hökfelt, Karolinska Institute, Stockholm, Sweden) or octapeptide (Bachem, Torrance, CA), and the CCK-US was an octapeptide (Bachem). Preliminary experiments in our laboratory demonstrated that sulfated CCK octapeptide was equipotent to the CCK heptapeptide we have used in previous studies (Hommer and Skirboll, 1983; Skirboll et al., 1981) both in its ability to potentiate APO-induced inhibition as well as in its ability to excite DA neurons. Apomorphine was obtained from Sigma Chemical Co. (St. Louis, MO). The CCK-4 and CCK-3 were gifts of Dr. P. Gaudreau, Notre Dame Hospital, Montreal.

After a DA unit was identified and a stable baseline was monitored for at least $5 \mathrm{~min}$, either CCK-S (20 $\mu \mathrm{g} / \mathrm{kg})$, CCK-US ( $20 \mu \mathrm{g} / \mathrm{kg})$, CCK-4 $(200 \mu \mathrm{g} / \mathrm{kg})$ or CCK-3 $(200 \mu \mathrm{g} / \mathrm{kg})$ was administered, followed $4 \mathrm{~min}$ later by APO. These doses were chosen based on reported affinities of these CCK fragments for the brain type CCK binding site. The APO dose-response curve was obtained with increasing drug doses administered at 2 min intervals until the neuronal activity was completely inhibited. Haloperidol $(0.1 \mathrm{mg} / \mathrm{kg})$ was subsequently administered to 


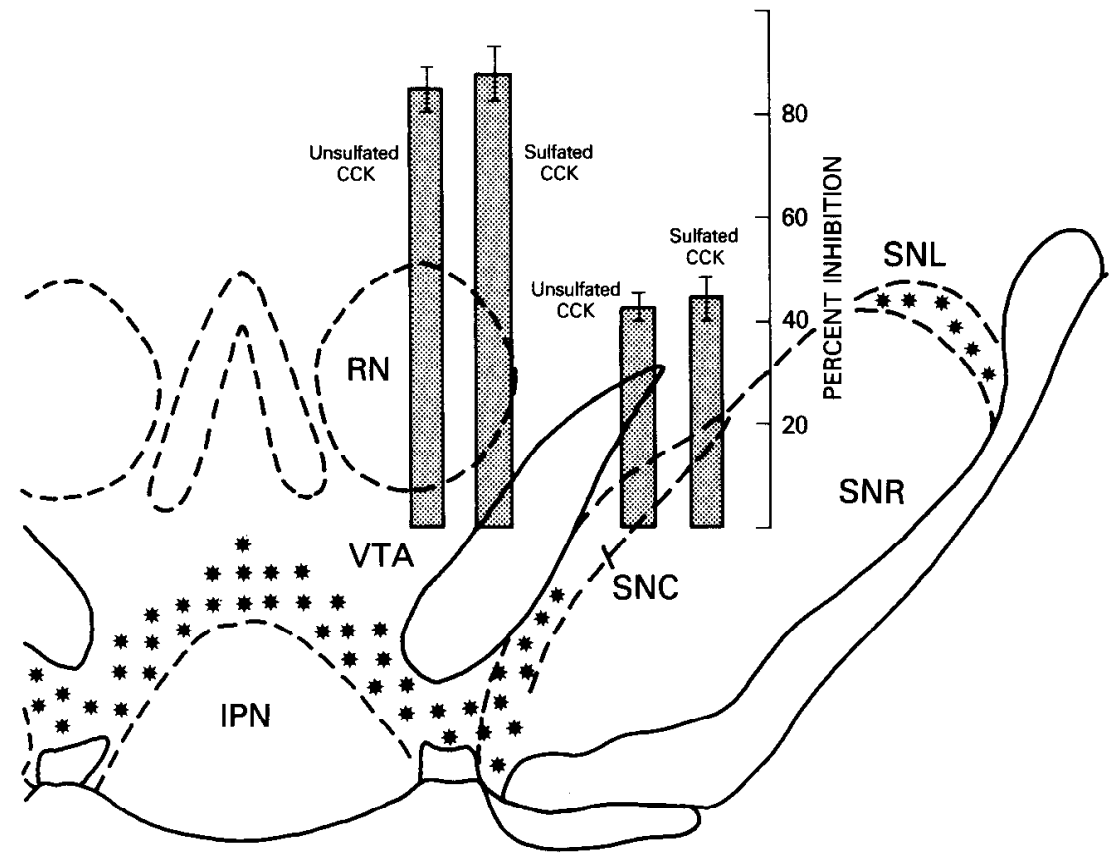

Figure 4. Bars indicating the effect of pretreatment with either sulfated or unsulfated CCK on the inhibition of DA cell firing produced by $8 \mu \mathrm{g} / \mathrm{kg}$ of APO are superimposed on a schematic drawing of a sagittal section of the rat mesencephalon. Stars indicate regions of DA/CCK coexistence. Medial-lateral location of the bars illustrates the regions from which cells were recorded $(n=6$ for each pretreatment and location). CCK-like peptides potentiate APO-induced inhibition only in regions in which DA and CCK coexist.

reverse the APO-induced inhibition and to insure that the absence of activity reflected true pharmacological inhibition and not merely movement of the electrode away from the cell. Only 1 cell was studied per animal. The effects of pretreatment with CCK-S and CCK-US on APOinduced inhibition was examined in both SN-VT and LCZ. The effects of CCK-3 or CCK-4 pretreatment were examined in the SN-VT region only. The effects of the various CCK peptides are expressed as the mean percentage change in firing rate + SEM

\section{Results}

\section{Excitatory effects of CCK analogs}

Of the $4 \mathrm{CCK}$-like peptides tested only the sulfated form of CCK produced an increase in SN-VT DA neuron activity. CCK-S administration $(20 \mu \mathrm{g} / \mathrm{kg}$, i.v. $)$ produced a $47.8 \pm 12.6 \%$ increase in neuronal activity, while CCK-US, CCK-4, and CCK-3 were all without any excitatory effects (Fig. 1). One-way analysis of variance (ANOVA) revealed that the effect of CCK-S was highly significant $(F(3,20)=12.8, p<0.001 ; n=6)$.

\section{Effect of CCK-like peptides on response to DA agonist}

In contrast to our findings with regard to excitation, pretreatment of DA cells in the SN-VT region with either CCK-S (20 $\mu \mathrm{g} / \mathrm{kg}$, i.v.) or CCK-US (20 $\mu \mathrm{g} / \mathrm{kg}$, i.v.) produced a left shift and resulted in a significant increase in the sensitivity of SN-VT DA neurons to apomorphine (Fig. 2). Similarly, the sensitivity of SN-VT neurons to apomorphine was also increased following pretreatment with CCK-4 (200 $\mu \mathrm{g} / \mathrm{kg}$, i.v.). CCK-3 (200 $\mu \mathrm{g} / \mathrm{kg}$, i.v.), however, failed to alter the sensitivity of DA neurons to apomorphine as compared to saline (Fig. $3 ; n=6$ for all groups).

ANOVA dcmonstrated a highly significant effect of the various pretreatments on the percentage inhibition of neuronal firing produced by a cumulative dose of $8 \mu \mathrm{g} / \mathrm{kg}$ APO $(\mathrm{F}(6,27)=$ $13.0, p<0.001)$. Post hoc Duncan's multiple-range test confirmed that pretreatment with CCK-S, CCK-US, and CCK-4 potentiated the effects of APO, while those of CCK-3 pretrcatment were no different from saline pretreatment $(p<0.01)$. Table 1 presents a comparison of the various CCK-like peptides on firing rate and DA sensitivity compared with their reported binding to brain and peripheral CCK receptors.

\section{Localization of the effects of CCK-like peptides}

We confirmed earlier studies that the excitatory action of CCK-S was confined to areas of the mesencephalon in which immunohistochemical studies have shown both CCK-like and tyrosine hydroxylase immunoreactivity. In areas of DA-CCK coexistence (SN-VT), CCK-S produced a $47.8 \pm 12.6 \%$ increase in the activity of DA cells, while in areas with few CCK-containing cell bodies, administration of the sulfated form of the peptide produced only a $3.4 \pm 2.1 \%$ increase. In addition, we found that the ability of CCK-S and/or CCK-US to increase APO sensitivity was also limited to areas richest in CCK-DA coexistence (Fig. 4). Pretreatment with either peptide coincidental to recordings in the $\mathrm{LCZ}$ resulted in $\mathrm{APO}$-induced in hibition no different than that seen following saline pretreatment.

\section{Discussion}

\section{Correlation with sites of coexistence}

In the central nervous system, CCK-like immunoreactivity has been demonstrated in neuronal perikarya and processes in sev-

Table 1. Comparison of the electrophysiological and biochemical effects of CCK-like peptides

\begin{tabular}{|c|c|c|c|c|}
\hline & \multicolumn{2}{|c|}{ Electrophysiology } & \multicolumn{2}{|c|}{ Biochemistry ${ }^{a}$} \\
\hline & $\begin{array}{l}\text { Potenti- } \\
\text { ation of } \\
\mathrm{APO}\end{array}$ & $\begin{array}{l}\text { Excita- } \\
\text { tion }\end{array}$ & $\begin{array}{l}\text { Affinity for } \\
\text { central site }\end{array}$ & $\begin{array}{l}\text { Affinity for } \\
\text { peripheral } \\
\text { site }\end{array}$ \\
\hline CCK-S & +++ & $++t$ & +++ & +++ \\
\hline CCK-US & +++ & - & $++1++t$ & - \\
\hline CCK-4 & ++ & - & ++ & - \\
\hline CCK-3 & - & - & - & - \\
\hline
\end{tabular}

${ }^{a}$ Data from Gaudreau et al. (1985), Van. Dijk et al. (1984), Wennogle et al. (1984) Steigerwalt and Williams (1984), Knight et al. (1984), Saito et al. (1981), Hays et al. (1980). 
eral specific areas, including the cerebral cortex, substantia nigra, and limbic system; the latter 2 have been implicated as coexistent systems with DA. Detailed immunohistochemical examination of these coexistent neurons has revealed that in the midbrain, DA-containing cells are more numerous than CCKDA cells and that some proportion of cells appears to be only CCK immunoreactive (Hökfelt et al., 1980a, b).

We have previously reported that the excitatory effects of CCK were limited to areas that demonstrated the richest CCKDA coexistence. More recently, we found that CCK exerts a separate and potent action in the substantia nigra, i.e., its ability to facilitate the actions of APO. In the present study, we explored the relationship between regional CCK-DA coexistence and the ability of CCK to facilitate the actions of APO. We found a close correlation between the ability of CCK-like peptides to modulate the actions of DA and immunohistochemical maps of CCK-DA coexistence. These data are similar to those reported by Crawley et al. (1985b), in which topographic examination of the CCK-induced potentiation of DA-induced hyperlocomotion was limited exclusively to sites which show CCK-DA coexistence in the nucleus accumbens. Thus, functional interactions between CCK and DA appear to be limited to the areas of the midbrain in which these 2 putative transmitters have been found to coexist.

\section{Correlation with $C C K$ binding sites}

We have previously reported that CCK-S is a potent neuromodulator in the substantia nigra, where it appears to have 2 actions: excitatory and facilitatory to the inhibitory effects of DA (Hommer and Skirboll, 1983; Skirboll et al., 1981). Earlier work has indicated that there arc spccific binding sites in the brain for CCK (Hays et al., 1980; Saito et al., 1980) and that the distribution of these binding sites corresponds to specific nuclei in the brain that show CCK-like immunoreactivity (Gaudreau et al., 1983; Van Dijk et al., 1984; Zarbin et al., 1983). It has, in fact, been suggested that there are multiple CCK receptor subtypes (Innis and Snyder, 1980). It seems clear from structureactivity studies that the $\mathrm{CCK}$ receptor demonstrated by radioligand binding in brain is different than receptors demonstrated in peripheral tissues (Gaudreau et al., 1983; Hays et al., 1980; Knight et al., 1984; Saito et al., 1980; Steigerwalt and Williams, 1984; Van Dijk et al., 1984; Wennogle et al., 1984). The results of the present study show that in discrete areas of the substantia nigra only CCK-8-S increased the firing rate of DA neurons, while CCK-8-US, CCK-4, and CCK-3 were ineffective. In contrast, both the sulfated and unsulfated forms of CCK-8, as well as CCK-4, effectively potentiated the actions of APO; only CCK-3 failed to elicit this response.

Detailed studies on the binding of CCK fragments to brain CCK receptors have revealed consistent structure-activity relationships with regard to binding potency. Several laboratories have reported that in brain, in contrast to in the pancreas, CCK-S is approximately equipotent to CCK-US, and both of these analogs are only slightly more potent than $\mathrm{CCK}-4$; binding of fragments smaller than CCK 30-33 (CCK-3), however, showed virtually no affinity (Gaudreau et al., 1983; Hays et al., 1980; Knight et al., 1984; Saito et al., 1980; Van Dijk et al., 1984). A comparison of the electrophysiological effects of CCK peptides and their affinity for brain binding sites reveals a positive correlation with only 1 of the 2 effects of CCK, i.e., the ability of CCK-like peptides and fragments to potentiate the inhibitory actions of APO.

Thus, the results of experiments on the abilities of CCK fragments to produce excitation suggest that this action is not mediated through the central high-affinity $\mathrm{CCK}$ receptor but rather through the so-called peripheral receptor site. CCK-I JS was reported to be up to 1000 times less potent than the sulfated CCK-8 in displacing ${ }^{125}$ I-CCK-33 binding from pancreatic aci- nor cells (Jensen et al., 1980). In addition, CCK-4 and CCK-3 showed virtually no affinity to peripheral binding sites (Van Dijk et al., 1984). These data suggest that the ability of CCK to increase the firing rate of DA neurons reflects an action at a receptor that most closely resembles the peripheral CCK receptor. This is of particular interest in light of findings that at least $50 \%$ of the excitatory actions of peripherally administered CCK can be attenuated by lesions of the nucleus tractus solitarius (Hommer et al., 1985).

In summary, the observation that certain CCK fragments interact differently with CNS and peripheral receptors suggests the possibility that the 2 distinct electrophysiologic actions of CCK may reflect activity at 2 different receptor sites. Since we administered CCK-like peptides systemically, we cannot exclude the possibility that they act at a site outside the CNS. However, our findings of an exact correspondence between the APO potentiating action of CCK peptides and their affinity for the brain-type CCK binding site suggest that this effect is probably centrally mediated. Our data also suggest that the processing of CCK from propeptide (CCK 33) to smaller CCK fragments may change dramatically the selectivity of the peptide for its receptor subtypes and thus its physiological actions. Further, sulfation and (or) desulfation may be involved in modifying the biological activity of $\mathrm{CCK}$ by directly changing the peptides affinity for a specific receptor subtype. The distribution and selectivity of the various processing or metabolic enzymes for CCK could thus be responsible for the generation of multiple signals from the same precursor peptide.

\section{References}

Bunney, B. S., J. R. Walters, R. H. Roth, and G. K. Aghajanian (1973) Dopaminergic neurons: Effects of antipsychotic drugs and amphetamine on single cell activity. J. Pharmacol. Exp. Ther. 185: 560-571.

Crawley, J. N., S. St. Pierre, and P. Gaudreau (1984) Analysis of the behavioral activity of $\mathrm{C}$ - and $\mathrm{N}$ - terminal fragments of cholecystokinin octapeptide. J. Pharmacol. Exp. Ther. 230: 438-444.

Crawley, J. N., J. A. Stivers, L. K. Blumstein, and S. M. Paul (1985a) Cholecystokinin potentiates dopamine-mediated behaviors: Evidence for modulation specific to a site of co-existence. J. Neurosci. 5: 1972-1983.

Crawley, J. N., D. W. Hommer, and L. R. Skirboll (1985b) Topographical analysis of nucleus accumbens sites at which cholecystokinin potentiates dopamine-induced hyperlocomotion in the rat. Brain Res. 335: 337-341.

Dodd, J., and J. S. Kelly (1981) The actions of cholecystokinin and related peptides on pyramidal neurons of the mammalian hippocampus. Brain Res. 205: 337-350.

Fuxe, K., L. Agnati, F. Benfenati, M. Cimmino, S. Algeri, T. Hökfelt, and V. Mutt (1981) Modulation by cholecystokinins of ${ }^{3} \mathrm{H}$-spiroperidol binding in rat striatum: Evidence for increased affinity and reduction in number of binding sites. Acta Physiol. Scand. 113: 567569.

Gaudreau, P., R. Quirion, S. St. Pierre, and C. B. Pert (1983) Tritiumsensitive film autoradiography of $\left[{ }^{3} \mathrm{H}\right]$ cholecystokinin-5/pentagastrin receptors in rat brain. Eur. J. Pharmacol. 87: 173-174.

Grace, A. A., and B. S. Bunncy (1980) Nigral dopamine ncurons: Intracellular recording and identification with L-dopa injection and histofluorence. Science 210: 654-656.

Hays, S. E., M. C. Beinfeld, R. T. Jensen, F. K. Goodwin, and S. M. Paul (1980) Demonstration of a putative receptor site for cholecystokinin in rat brain. Neuropeptides 1: 53-62.

Hökfelt, T., L. Skirboll, J. F. Rehfeld, M. Goldstein, K. Markey, and O. Dann (1980a) A subpopulation of mesencephalic dopamine neurons projecting to limbic areas contains a cholecystokinin-like peptide: Evidence from immunohistochemistry combined with retrograde tracing. Neuroscience 5: 2093-2124.

Hökfelt, T., J. F. Rehfeld, L. Skirboll, B. Ivemark, M. Goldstein, and K. Markey (1980b) Evidence for coexistence of dopamine and CCK in meso-limbic neurones. Nature 285: 476-478.

Hommer, D., and L. Skirboll (1983) Cholccystokinin-likc peptides potentiate apomorphine-induced inhibition of dopamine neurons. Eur. J. Pharmacol. 91: 151-152. 
Hommcr, D., M. Palkovites, J. Crawley, S. Paul, and L. Skirboll (1985) Cholecystokinin-induced excitation in the substantia nigra: Evidence for peripheral and central components. J. Neurosci. 5: 1387-1392.

Innis, R. B., and S. H. Snyder (1980) Cholecystokinin receptor binding in brain and pancreas: Regulation of pancreatic binding by cyclic and acyclic guanine nucleotides. Eur. J. Pharmacol. 65: 123-124.

Jeftiniji, S., V. Miletic, and M. Randic (1981) CCK8 excites dorsal horn neurons both in vivo and in vitro. Brain Res. 213: 231-236.

Jensen, R. T., G. F. Lemp, and J. D. Gardner (1980) Interaction of cholecystokinin with specific membrane receptors on pancreatic acinar cells. Proc. Natl. Acad. Sci. USA 77: 2079-2083.

Knight, M., C. A. Tamminga, L. Steardo, M. E. Beck, P. Barone, and T. N. Chase (1984) Cholecystokinin-octapeptide fragments binding to brain cholecystokinin receptors. Eur. J. Pharmacol. 105: 49-55.

Markstcin, R., and T. Hökfclt (1984) Effcet of cholccystokinin-octapeptide on dopamine release from slices of cat caudate nucleus. J. Neurosci. 4: 570-575.

Meyer, D. K., and J. Krause (1983) Dopamine modulates cholecystokinin release in neostriatum. Nature 301: 338-340.

Moran, T. H., P. H. Robinson, and P. R. Mchugh (1985) The pyloric cholecystokinin receptor in neuronal cholecystokinin. Ann. NY Acad. Sci. 448: 621-623.

Murphy, R. B., and D. I. Schuster (1983) Modulation of $\left[{ }^{3} \mathrm{H}\right]$ dopamine binding by cholecystokinin octapeptide (CCK-8). Peptides 3: 539543

Paxinos, G., and C. Watson (1982) The Rat Brain in Stereotaxic Coordinates, Academic, Sydney.

Pinget, M., E. Straus, and R. S. Yalow (1979) Release of cholecystokinin peptide from a synaptosomc-cnriched fraction of rat ccrcbral cortex. Life Sci. 25: 339-342.

Rogawski, M. A. (1982) Cholecystokinin octapeptide: Effects on excitability of cultured spinal neurons. Peptides 3: 545-551.

Saito, A., H. Sankaran, I. D. Goldfine, and J. A. Williams (1980)
Cholccystokinin reccptors in brain: Characterization and distribution. Science 208: 1155-1156.

Salt, T. E., and R. G. Hill (1982) The effects of c-terminal fragments of cholecystokinin on the firing of single neurons in the caudal trigeminal nucleus of the rat. Neuropeptides 2: 301-306.

Skirboll, L. R., A. Grace, and B. S. Bunney (1979) Dopamine preand postsynaptic receptors: Electrophysiological evidence for differential sensitivity to dopamine agonists. Science 206: 80-82.

Skirboll, L. R., A. A. Grace, D. W. Hommer, J. Rehfeld, M. Goldstein, T. Hökfelt, and B. S. Bunney (1981) Peptide monoamine coexistence: Studies of actions of cholecystokinin-like peptide on the electrical activity of midbrain dopamine neurons. Neuroscience 6:21112124.

Steigerwalt, R. W., and J. A. Williams (1984) Binding specificity of the mouse cercbral cortex receptor for small cholecystokinin peptides. Regulat. Peptides 8: 51-59.

Van Dijk, A., J. G. Richards, A. Trzeciak, D. Gillessen, and H. Moler (1984) Cholecystokinin receptors: Biochemical demonstration and autoradiographical localization in rat brain and pancreas using $\left[{ }^{3} \mathrm{H}\right]$ cholecystokinin-8 as radioligand. J. Neurosci. 4: 1021-1033.

Voight, M. M., and R. Y. Wang (1984) In vivo release of dopamine in nucleus accumbens of the rat: Modulation by cholecystokinin. Brain Res. 296: 189-193.

Wennogle, L., D. J. Steel, and B. Petrack (1985) Characterization of central cholecystokinin receptors using a radiodinated octapeptide probe. Life Sci. 36: 1485-1492.

White, F. J., and R. Y. Wang (1984) Interactions of cholecystokinin octapeptide and dopamine on nucleus accumbens neurons. Brain Res. 300: 161-166.

Zarbin, M. A., R. B. Innis, J. K. Wamsley, S. H. Snyder, and M. J. Kuhar (1983) Autoradiograph localization of cholecystokinin receptors in rodent brain. J. Neurosci. 3: 877-906. 